\title{
PRODUÇÃO DE INÓCULO DE ALTERNARIA CASSIAE
}

\author{
ZILÁ RIBEIRO DE ÁVILA², SUELI CORRÊA MARQUES DE MELLO ${ }^{3}$, \\ ZILDA MARIA DE ARAÚJO RIBEIRO ${ }^{4}$ e ELIANA MARIA GOUVEA FONTES ${ }^{5}$
}

\begin{abstract}
RESUMO - Visando ajustar metodologia de produção de inóculo, um isolado do fungo Alternaria cassiae, selecionado como agente para biocontrole de fedegoso (Senna obtusifolia), foi estudado quanto ao crescimento micelial e esporulação em diferentes meios de cultura e condições de cultivo. Meio V-8 caseiro sem adição de $\mathrm{CaCO}_{3}$, incubação em volume de $200-250 \mathrm{~mL}$ de meio (cerca de $50 \%$ do volume do frasco), período de 48 horas de agitação a 250 rpm, seguida de exposição da massa micelial em escuro contínuo foram as condições que se mostraram mais adequadas para a produção de inóculo em larga escala. A esporulação foi favorecida por incubação da massa micelial a $25^{\circ} \mathrm{C}$. A adoção de $300 \mathrm{~mL}$ de massa fúngica por bandeja $(29,9$ x 44,5 x 5,0 cm) possibilitou secagem rápida, assegurando a integridade dos conídios, refletida na maior infectividade do inóculo produzido.
\end{abstract}

Termos para indexação: biocontrole, Senna obtusifolia, micoerbicida.

\section{PRODUCTION OF ALTERNARIA CASSIAE INOCULUM}

\begin{abstract}
In order to adjust the methodology of inoculum production, an isolate of the fungus Alternaria cassiae, selected as a biological control agent for sicklepod (Senna obtusifolia) was studied under different culture media and mycelial growth conditions. Homemade V-8 juice medium without $\mathrm{CaCO}_{3}$ addition, incubation on $200-250 \mathrm{~mL}$ of medium (around $50 \%$ of the flask volume) with agitation at $250 \mathrm{rpm}$ during 48 hours, followed by mycelial mass growth in continuous dark were appropriate conditions for a large scale production of inoculum. The sporulation was aided by incubation of the mycelial mass at $25^{\circ} \mathrm{C}$. The use of $300 \mathrm{~mL}$ of mycelial mass per pan $(29.9$ by 44.5 by $5.0 \mathrm{~cm})$ to induce the sporulation provided rapid dryness and ensured the conidium integrity, indicated by higher infectivity of the inoculum.
\end{abstract}

Index terms: biological control, Senna obtusifolia, mycoherbicide.

\section{INTRODUÇÃO}

O fedegoso (Senna obtusifolia L.) tem assumido grande importância como infestante em cultivos de soja (Glycine max L.), no Brasil. De acordo com Pitelli (1992), este fato deve-se à incorporação, ao longo dos anos, de novas áreas de plantio e ao aumento da diversidade de produtos herbicidas

\footnotetext{
${ }^{1}$ Aceito para publicação em 9 de junho de 1999.

Trabalho conduzido com suporte financeiro de CNPq.

${ }^{2}$ Eng. Agrôn., M.Sc. Bolsista do RHAE.

${ }^{3}$ Eng. Agrôn., Dra., Embrapa-Centro Nacional de Pesquisa de Recursos Genéticos e Biotecnologia (Cenargen), SAIN Parque Rural, Caixa Postal 02372, CEP 70849-970 Brasília, DF. E-mail: smello@ cenargen.embrapa.br

${ }^{4}$ Bióloga, M.Sc., Embrapa-Cenargen.

${ }^{5}$ Bióloga, Ph.D., Embrapa-Cenargen.
}

seletivos para a cultura, dada a proximidade genética entre as duas espécies. Também no sul dos Estados Unidos esta planta daninha constitui problema na soja e outras oleaginosas, como amendoim (Arachis hypogaea L.) e algodão (Gossypium hirsutum L.) (Walker, 1983; Charudattan et al., 1986). A resistência dessa planta a herbicidas (Crowley et al., 1979) vem tornando-a um alvo ideal para o desenvolvimento de programas de controle biológico, na busca de alternativas de controle mais eficientes.

O fungo Alternaria cassiae Jurair \& Khan (Simmons, 1982) vem sendo estudado para controle desta planta daninha nos Estados Unidos, com os primeiros resultados positivos obtidos no estado do Mississipi (Walker, 1983). A partir de então, vários estudos foram feitos, demonstrando a eficácia de A. cassiae no controle do fedegoso em condições de campo, em cinco estados do sul dos Estados Uni- 
dos, onde um isolado desse fungo alcançou a fase de registro como micoerbicida (Charudattan et al., 1986; Charudattan, 1996).

Um isolado de A. cassiae foi obtido de plantas de fedegoso exibindo manchas necróticas no limbo dos folíolos, coletadas no Distrito Federal, e depositado no Banco de Germoplasma de fungos fitopatogênicos da Embrapa-Centro Nacional de Pesquisa de Recursos Genéticos e Biotecnologia (Cenargen), sob o número de acesso CG593. Atualmente este isolado encontra-se em fase de avaliação em casa de vegetação e no campo (Mello \& Ribeiro, 1998). Vários experimentos conduzidos revelaram que o controle do fedegoso com este isolado do fungo pode ser total, se aplicado durante o estádio de plântulas.

Esse patógeno esporulou profusamente em V-8-ágar (Walker, 1982), mas a produção em larga escala é impraticável em placas de Petri. Esporos de A. cassiae não são produzidos em culturas submersas. Diante disso, um método para obtenção de grande quantidade de inóculo, associando produção de micélio sob fermentação líquida seguida de esporulação e secagem em bandejas foi desenvolvido por Walker (1982). Este método baseia-se no cultivo do fungo em meio V-8 industrial acrescido de $\mathrm{CaCO}_{3}$ sob vigorosa rotação durante $24-72$ horas e exposição da massa micelial à luz solar, para esporulação.

O objetivo deste trabalho foi determinar as condições ideais para crescimento e esporulação do isolado CG593 de A. cassiae, para o desenvolvimento de um processo de produção massal desse fungo, a partir da metodologia proposta por Walker (1982).

\section{MATERIAL E MÉTODOS}

O isolado CG593 de Alternaria Cassiae, preservado a $10^{\circ} \mathrm{C}$, foi cultivado em BDA durante sete dias, sendo o micélio produzido triturado em água estéril e utilizado como inóculo semente (5\% v/v), em todos os experimentos.

A não ser nos casos especificados, os procedimentos experimentais foram os seguintes: o meio utilizado foi à base de suco V-8 caseiro, produzido conforme descrito por Borges Neto (1997) (200 mL/L), e sacarose (15 g/L), com pH ajustado em 5,5 antes da esterilização. A incubação ocorreu imediatamente após a repicagem do inóculo para o meio, em agitador (Lab-line incubator-shaker) a
$250 \mathrm{rpm}$ e $25^{\circ} \mathrm{C}$. A massa micelial obtida foi homogeneizada em liquidificador por 30 segundos e vertida em bandejas de alumínio $(29,9 \times 44,5 \times 5,0 \mathrm{~cm})$, ao volume de $600 \mathrm{~mL} /$ bandeja, para esporulação e secagem ao ar.

As culturas foram incubadas no escuro, dispostas em prateleiras, em uma sala especialmente construída para incubação de fungos, com fotoperíodo controlado. A temperatura foi mantida em torno de $25^{\circ} \mathrm{C}$ e a umidade, variando de 50 a $70 \%$ no período da realização dos experimentos.

Os propágulos foram coletados das bandejas com o auxílio de um pincel de pêlo de camelo e estocados em frascos de vidro transparente hermeticamente fechados, a $8^{\circ} \mathrm{C}$. O número de esporos por grama de massa fúngica produzida foi determinado tomando-se a média de três leituras em hemocitômetro a partir de uma suspensão preparada $(5 \mathrm{mg}$ por $10 \mathrm{~mL}$ de água destilada acrescida de Tween 20 - polioxietileno sorbitan monolaurate a $0,02 \%$ ).

Os testes de viabilidade de inóculo foram realizados em placas de Petri contendo o meio água-ágar, depositando-se $200 \mu \mathrm{L}$ de suspensão de esporos à concentração de $1 \times 10^{5}$ esporos/mL, na superfície do meio. De cada tratamento, em todos os experimentos conduzidos, foram preparadas três placas, as quais foram mantidas a $25^{\circ} \mathrm{C}$, por cerca de 24 horas. De cada placa, determinou-se a porcentagem de esporos germinados, por meio de contagens sob microscópio.

Para os testes de infectividade de inóculo, sementes de fedegoso foram escarificadas com ácido sulfúrico concentrado (95-97\% p.a.), por oito minutos, lavadas com água corrente e pré-germinadas em placas de Petri, em condições ambientes. As plântulas foram transferidas para vasos de plástico de 0,5 litro de capacidade, contendo solo autoclavado, em casa de vegetação. O substrato utilizado nos experimentos consistiu da seguinte mistura: terra, esterco de gado curtido e areia lavada de rio, na proporção de 2:1:1, fertilizada com $33 \mathrm{~g} / \mathrm{L}$ de calcário dolomítico e $17 \mathrm{~g} / \mathrm{L}$ de superfosfato simples. Os experimentos foram conduzidos em blocos ao acaso, com quatro repetições, consistindo, a unidade experimental, de um vaso com cinco plantas.

As inoculações foram feitas aspergindo-se as plântulas, nos estádios cotiledonares até duas folhas definitivas, com suspensões fúngicas ( $5 \times 10^{5}$ esporos $\left./ \mathrm{mL}\right)$. Após a inoculação, as plantas foram incubadas sob sacos de plástico transparentes, previamente umedecidos, e mantidas debaixo das bancadas para evitar insolação direta nas primeiras 48 horas, sendo então retiradas dos sacos de plástico e recolocadas sobre as bancadas da casa de vegetação $\left(23-40^{\circ} \mathrm{C}\right)$.

A severidade foi determinada até 10 dias após inoculação, utilizando-se uma escala de notas variando de 
1 a 9 , onde 1 significa ausência de sintomas e 9, significa morte da planta. A incidência da doença foi também avaliada, em termos de porcentagem de plantas mortas.

Todos os experimentos foram repetidos pelo menos duas vezes.

\section{Efeito de meios de cultura na produção de inóculo de} A. cassiae

A produção massal de inóculo de $A$. cassiae foi avaliada nos seguintes meios: suco V-8 caseiro (V-8C), sucos de tomate das marcas Campbel (TIC) e Super Bom (TSB) e de confecção caseira (TC), batata-cenouradextrose (BCD) e batata-dextrose (BD). Para os meios TIC, TSB e TC, foram empregadas $3 \mathrm{~g}$ de $\mathrm{CaCO}_{3}$ por litro de meio preparado a partir de $230 \mathrm{~mL}$ de suco de tomate concentrado. Para a confecção do suco de tomate caseiro, foram utilizados os procedimentos descritos por Borges Neto (1997) para o suco V-8 caseiro, mantendose o tomate e suprimindo os demais ingredientes. O meio $\mathrm{BCD}$ foi preparado a partir do cozimento de $100 \mathrm{~g}$ de batatas e $100 \mathrm{~g}$ de cenoura em $1.000 \mathrm{~mL}$ de água destilada. $\mathrm{O}$ material foi filtrado em gaze, adicionado de $15 \mathrm{~g}$ de dextrose, completando-se o volume para um litro. O meio BD foi preparado de maneira idêntica, utilizando-se $200 \mathrm{~g}$ de batata e $15 \mathrm{~g}$ de dextrose. Antes da autoclavagem, todos os meios tiveram o $\mathrm{pH}$ ajustado para 5,5 e foram distribuídos em frascos Erlenmeyer de $500 \mathrm{~mL}$ de capacidade ( $150 \mathrm{~mL} /$ frasco), cada um recebendo $7,5 \mathrm{~mL}$ da suspensão de inóculo, preparada como descrito anteriormente. Realizaram-se cinco repetições por tratamento, cada frasco representando uma unidade experimental.

As avaliações foram realizadas em termos de rendimento de massa fúngica seca em gramas/litro de meio, concentração de esporos contida na massa fúngica (esporos/grama), viabilidade e infectividade do inóculo.

Efeito do volume de meio $\mathrm{x}$ tempo de incubação no desenvolvimento de $\boldsymbol{A}$. cassiae

Inicialmente, foi avaliado o rendimento de massa micelial utilizando-se os volumes de 50,75 e $100 \mathrm{~mL}$ de meio V-8 caseiro, dispostos em frascos Erlenmeyer de $250 \mathrm{~mL}$ de capacidade, inoculados com a suspensão fúngica a $5 \% \mathrm{v} / \mathrm{v}$. As colônias foram incubadas por períodos de 48, 60 e 72 horas. Após o período de agitação, a massa micelial foi coletada por filtragem a vácuo, submetida a secagem durante 48 horas em estufa a $70^{\circ} \mathrm{C}$, tomando-se o peso seco de cada repetição dos diferentes tratamentos. Cada Erlenmeyer constituiu uma repetição e quatro repetições foram adotadas por tratamento.

Em uma etapa posterior, este experimento foi realizado com volumes de 150,200 e $250 \mathrm{~mL}$ de meio em frascos de $500 \mathrm{~mL}$ de capacidade. A incubação das colônias ocorreu durante 48 e 72 horas, com agitação. A massa micelial foi induzida a esporular, tendo sido avaliados o rendimento de massa fúngica seca ( $\mathrm{g} / \mathrm{L}$ ) e a concentração de esporos.

\section{Efeito de diferentes concentrações de $\mathrm{CaCO}_{3}$ na pro-} dução de inóculo

Foram avaliados o rendimento de massa micelial, a esporulação e a infectividade do inóculo mediante o acréscimo de carbonato de cálcio $\left(\mathrm{CaCO}_{3}\right)$, nas proporções de 1,2 , e $3 \mathrm{~g} / \mathrm{L}$ do meio V-8 caseiro. As inoculações foram realizadas com $10 \mathrm{~mL}$ de suspensão micelial por frasco Erlenmeyer de $500 \mathrm{~mL}$ de capacidade, contendo $200 \mathrm{~mL}$ de meio de cultura e a incubação ocorreu conforme estabelecido no experimento anterior, durante 48 horas. Foram adotadas três repetições por tratamento, consistindo, a unidade experimental, de um Erlenmeyer.

Efeito da temperatura durante a exposição da massa micelial para esporulação e secagem, no rendimento e qualidade do inóculo

O efeito da temperatura durante a exposição da massa micelial para esporulação e secagem no rendimento de propágulos, concentração de esporos e infectividade do inóculo foi estudado em duas etapas. Na primeira etapa, foram conduzidos dois experimentos: o primeiro, testando-se as temperaturas de 20 e $25^{\circ} \mathrm{C}$, e o segundo, além destas, testando-se também a temperatura de $30^{\circ} \mathrm{C}$. Na segunda etapa, foram testadas as temperaturas de 20, 25, 28 e $30^{\circ} \mathrm{C}$. Para avaliação, considerou-se o rendimento de massa fúngica, a concentração de esporos e a infectividade do inóculo.

Efeito do volume de massa micelial em bandejas sobre a produção de inóculo

Para determinar o volume ideal de micélio a ser vertido em bandejas para esporulação e secagem, foram testados $150,300,450,600$ e $700 \mathrm{~mL}$. O experimento foi conduzido em delineamento de blocos ao acaso, com cinco tratamentos (volumes de massa micelial) e quatro repetições, constituindo-se a unidade experimental de três bandejas. A massa fúngica obtida, em cada volume testado, foi coletada, e avaliada quanto ao rendimento e concentração de esporos. O tempo de secagem foi anotado em cada tratamento, e para verificar a influência destes tratamentos sobre a integridade dos esporos contidos na massa fúngica produzida, foram feitas montagens destas estruturas em lâminas com uma gota de lactofenol-azul de algodão, conforme Abbas et al. (1995). Cinqüenta conídios por trata- 
mento, tomados ao acaso, foram examinados ao microscópio ótico, usando aumento de $200 \mathrm{X}$, para verificação da porcentagem de conídios tingidos e determinação das características morfométricas. A viabilidade em meio ágarágua e infectividade a plântulas de fedegoso foi também determinada, de acordo com a metodologia descrita anteriormente.

Efeito da luminosidade na esporulação e na qualidade do inóculo

A influência da luminosidade na esporulação de A. cassiae foi estudada vertendo-se a massa micelial em bandejas de alumínio no volume de $300 \mathrm{~mL} /$ bandeja (estabelecido no experimento anterior), que foram submetidas a quatro regimes de luz diários: claro contínuo, escuro contínuo, 12 horas-luz/escuro e 24 horas-luz/escuro, a $25^{\circ} \mathrm{C}$. O claro correspondeu à iluminação obtida através de lâmpadas fluorescentes de $22 \mathrm{~W}$ instaladas a $30 \mathrm{~cm}$ de altura das bandejas e a $68 \mathrm{~cm}$ de distância entre si, em cada uma das prateleiras, fornecendo uma luminosidade média de 1.063 lux. O ambiente escuro foi atingido por luminosidade máxima de 10 lux. A distribuição dos tratamentos na sala de incubação foi inteiramente casualizada, com seis repetições, cada bandeja representando uma unidade experimental. As avaliações foram realizadas como nos experimentos anteriores. Determinou-se, ainda, o número médio de tubos germinativos por conídio germinado e tomaram-se as medidas morfométricas dos esporos, em cada tratamento. A porcentagem de conídios tingidos em lactofenol-azul de algodão foi avaliada, conforme descrito anteriormente.

\section{RESULTADOS E DISCUSSÃO}

Efeito de meios de cultura na produção de inóculo de $A$. cassiae

$\mathrm{O}$ meio $\mathrm{V}-8 \mathrm{C}$ proporcionou maior rendimento (g/L) de inóculo, seguido pelo meio TC. Entretanto, verificou-se maior concentração de esporos por grama de inóculo com o meio de suco de tomate da marca Super Bom (Fig. 1). Quanto à viabilidade dos esporos, o meio BD diferiu dos demais, apresentando os mais baixos valores de porcentagem de germinação em meio ágar-água. Não foi detectada diferença significativa $(\mathrm{p}=0,05)$ em relação à infectividade de inóculo produzido nos diferentes meios à plantas de fedegoso (Fig. 2).

A experiência bem sucedida com a utilização de meio à base V-8C está de acordo com relatos feitos por Smith \& Onions (1983). Segundo estes autores, certas culturas fúngicas crescem melhor em meios frescos preparados em laboratório. Esta experiência se repetiu quando se utilizaram meios à base de tomate exclusivamente, pois o meio de confecção ca-

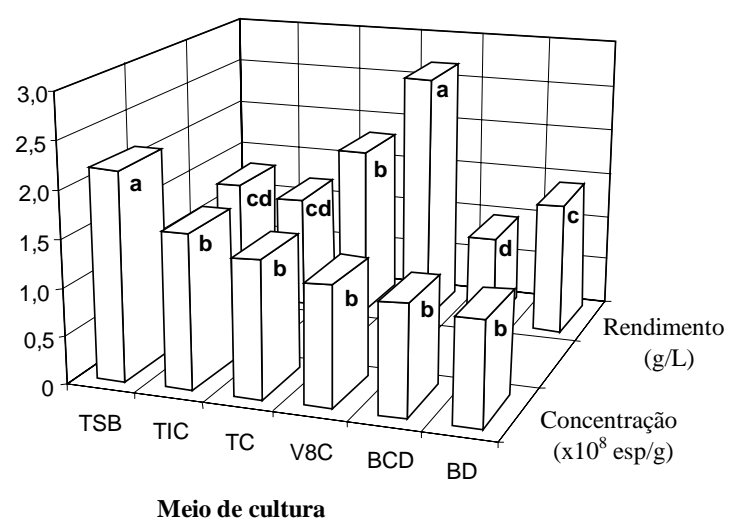

FIG. 1. Efeito de meios de cultura na produção de inóculo de Alternaria cassiae. (Meios de cultura: TSB - Suco de tomate Superbom; TIC - suco de tomate Campbel; TC - Suco de tomate caseiro; V-8C - Suco V-8 caseiro; BCD - Batata-cenoura-dextrose; BD - Batata-dextrose)

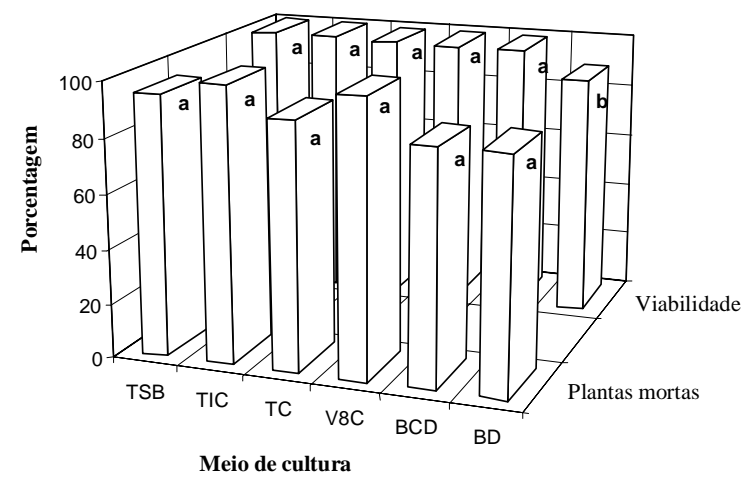

FIG. 2. Efeito de meios de cultura na viabilidade e infectividade de esporos de Alternaria cassiae. (Meios de cultura: TSB - Suco de tomate Superbom; TIC - suco de tomate Campbel; TC - Suco de tomate caseiro; V-8C - Suco V-8 caseiro; $B C D$ - Batata-cenoura-dextrose; BD - Batata-dextrose) 
seira (TC) superou os meios das duas marcas industriais testadas, em termos de rendimento de massa fúngica seca.

\section{Efeito do volume de meio $\mathrm{x}$ tempo de incubação no crescimento micelial}

A análise de variância revelou diferença significativa para volumes de meio, no tocante ao rendimento de massa micelial, com o período de incubação de 48 horas, tendo sido mais produtiva a incubação em $75 \mathrm{~mL}$ de meio por frasco de $250 \mathrm{~mL}$, ou seja, ocupando volume inferior a $1 / 3$ do frasco (Fig. 3 ). Interação entre volumes e tempo de incubação foi detectada, embora os tratamentos com 50 e $100 \mathrm{~mL}$ de meio não tenham diferido entre si. Também não houve diferença quanto aos períodos de incubação de 60 e 72 horas, com os volumes testados. O período de agitação de 48 horas foi também o que promoveu maior rendimento de massa fúngica avaliada na segunda etapa, não tendo sido detectada diferença significativa para os volumes de 250 e $200 \mathrm{~mL}$ de meio por frasco de $500 \mathrm{~mL}$, que entretanto foram superiores aos do tratamento com $150 \mathrm{~mL}$. Os tratamentos não diferiram entre si, no tocante à concentração de esporos por grama da massa fúngica obtida (Fig. 4).

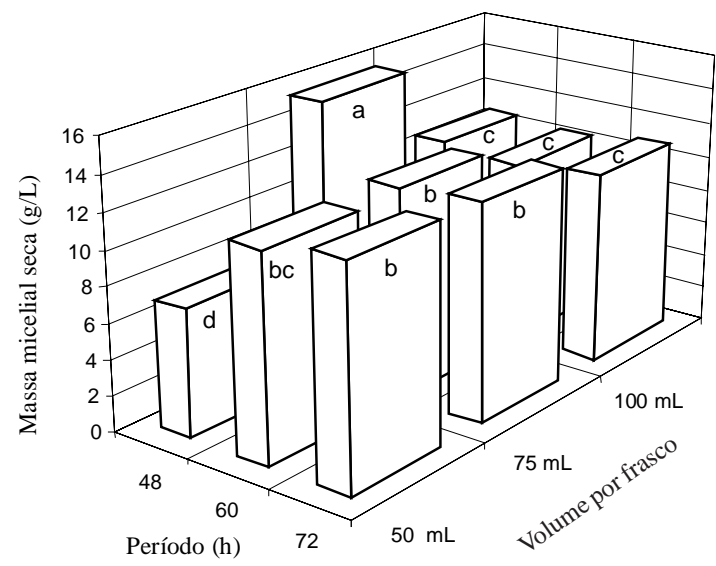

FIG. 3. Efeito do período de agitação e do volume de meio de cultura por frasco, no crescimento micelial de Alternaria cassiae.
A obtenção de maior rendimento de micélio em menor tempo é interessante, pois diminui as chances de contaminação durante a fase de crescimento das colônias, que pode ser um fator limitante para a obtenção de inóculo de boa qualidade. De acordo com os resultados obtidos, maior rendimento de massa micelial foi verificado com período de incubação de 48 horas, para qualquer um dos volumes de meio utilizados. Embora menor volume de meio por frasco possa favorecer a aeração, possibilitando melhor crescimento micelial das culturas de A. cassiae, não se observou, neste trabalho, um correspondente incremento no rendimento de inóculo final e/ou esporulação. Portanto, a utilização de 200-250 mL de meio por frasco de $500 \mathrm{~mL}$ (cerca da metade da capacidade do frasco) apresentou-se vantajosa, rendendo maior quantidade de inóculo por volume inicial de meio.

\section{Efeito de diferentes concentrações de $\mathrm{CaCO}_{3}$ na produção de inóculo}

O rendimento de massa micelial foi maior quando o meio foi acrescido de 2 e $3 \mathrm{~g} / \mathrm{L}$ de $\mathrm{CaCO}_{3}$, não diferindo significativamente do tratamento sem carbonato de cálcio (Fig. 5). A concentração de propágulos foi de $2 \times 10^{8}$ esporos/g, em todos os tratamentos. Quanto à infectividade, os valores médios de área abaixo da curva de progresso de doença

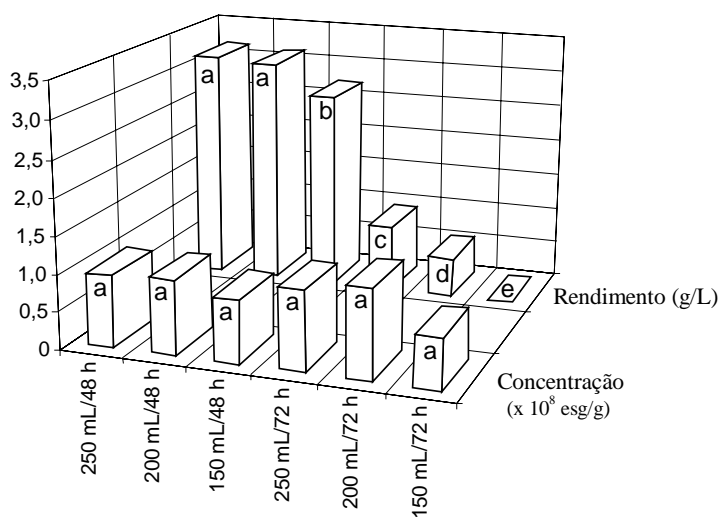

FIG. 4. Efeito do período de agitação e do volume de meio de cultura no frasco de incubação sobre a produção de inóculo de Alternaria cassiae.

Pesq. agropec. bras., Brasília, v.35, n.3, p.533-541, mar. 2000 
(AACPD) em plântulas de fedegoso, referentes a quatro leituras (Fig. 6), mostraram que o inóculo produzido sem acréscimo de $\mathrm{CaCO}_{3}$ foi mais eficiente, sem diferir, no entanto, dos tratamentos com 1 e $2 \mathrm{~g}$ da substância. Uma vez que os tratamentos não diferiram, a adoção do meio sem $\mathrm{CaCO}_{3}$ seria mais econômica.

Efeito da temperatura durante a exposição da massa micelial para esporulação e secagem, sobre o rendimento e qualidade do inóculo

A concentração de esporos/g de propágulos em todos os tratamentos variou entre $1,4 \times 10^{8}$ a $3 \times 10^{8}$, tendo sido maior na temperatura de $25^{\circ} \mathrm{C}$ (Fig. 7), na

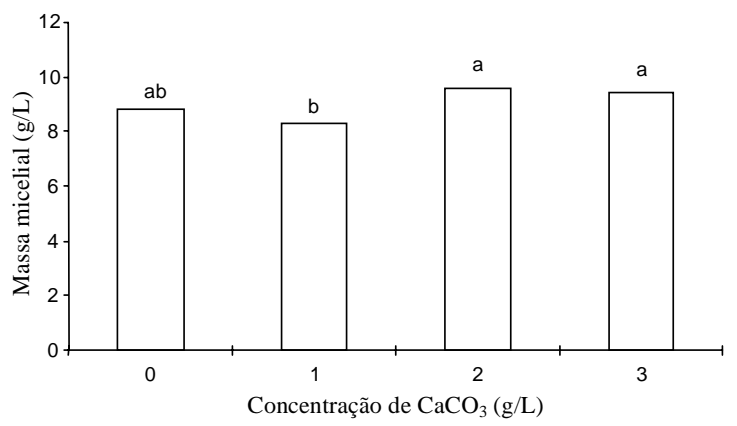

FIG. 5. Efeito de concentração de $\mathrm{CaCO}_{3}$ no crescimento micelial de Alternaria cassiae.

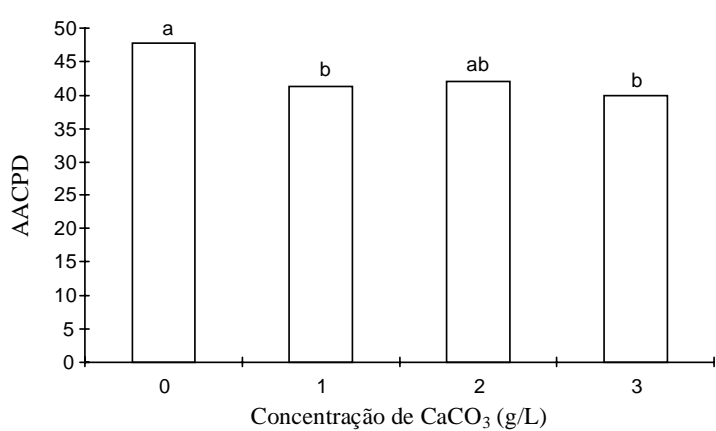

FIG. 6. Infectividade do inóculo de Alternaria cassiae produzido em meio $\mathrm{V}-8$ caseiro com diferentes concentrações de $\mathrm{CaCO}_{3^{*}}$ (AACPD: área abaixo da curva de progresso de doença) primeira etapa de experimentação. Nessa etapa, temperatura de $30^{\circ} \mathrm{C}$ proporcionou rendimento significativamente maior $(\mathrm{p}=0,05)$ de propágulos $(2,4 \mathrm{~g} / \mathrm{L}$ de meio), porém menor concentração de esporos $\left(1,4 \times 10^{8}\right.$ esporos/g). Entretanto, na segunda etapa, quando o volume de massa micelial vertido nas bandejas foi reduzido à metade $(300 \mathrm{~mL} /$ bandeja $)$, foram verificados também os maiores rendimentos, em termos de massa fúngica seca, à temperatura em torno de $25^{\circ} \mathrm{C}(\mathrm{p}=0,05)$ (Fig. 8). De acordo com Walker (1983), 1,5 g de propágulos secos contendo $9 \times 10^{7}$ esporos/g foram produzidos, por bandeja com 500 a $800 \mathrm{~mL}$ de homogeneizado de micélio, pelo método por ele descrito. Portanto, os valores obtidos nestes experimentos, tanto em rendimento de massa fúngica seca, quanto de concentração de esporos, estão adequados. Diante destes resultados, a temperatura de $25^{\circ} \mathrm{C}$ passou a ser adotada como padrão para incubação do micélio durante os trabalhos rotineiros de produção de inóculo de $A$. cassiae.

Quanto à infectividade, os resultados foram inconsistentes, tendo, o inóculo incubado a $25^{\circ} \mathrm{C}$, no primeiro teste, sido mais infectivo. No entanto, os danos causados ao fedegoso por propágulos produzidos a 20 e $30^{\circ} \mathrm{C}$, no segundo teste, não diferiram entre si e foram mais expressivos do que os produzidos a $25^{\circ} \mathrm{C}$. Portanto, há necessidade de se avaliar melhor os efeitos da temperatura de incubação du-

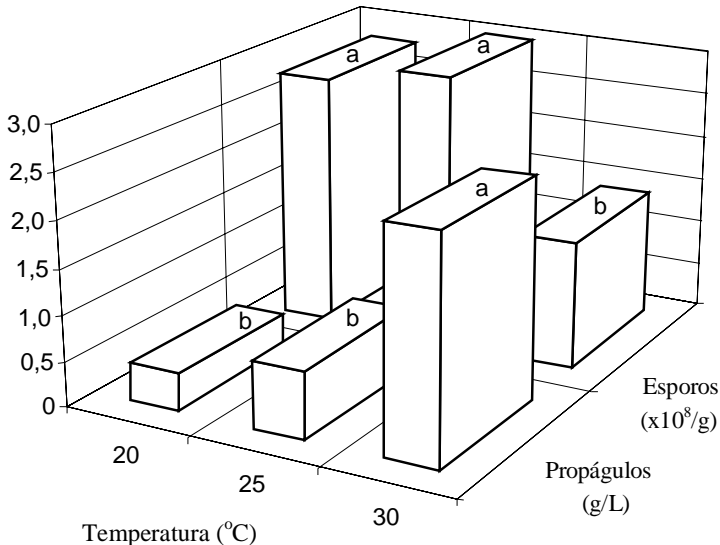

FIG. 7. Esporulação de Alternaria cassiae sob diferentes temperaturas. 
rante o processo de produção de conídios A. cassiae, na infectividade a plantas de fedegoso.

\section{Efeito do volume de massa micelial em bandejas sobre a produção de inóculo}

De acordo com a análise de variância, não foi detectada diferença significativa entre os tratamentos, em termos de rendimento de inóculo $(\mathrm{g} / \mathrm{L})$ $(\mathrm{p}=0,05)$. Não obstante, observou-se maior concentração de esporos por grama de inóculo com o volume de $150 \mathrm{~mL}$ (Fig. 9). Quanto à viabilidade dos conídios em ágar-água, foi detectada diferença significativa em relação ao volume de $600 \mathrm{~mL}$, que proporcionou porcentual germinativo inferior aos demais (Fig. 10). Os testes de infectividade em plantas de fedegoso revelaram maior severidade de sintomas com inóculo produzido com menores volumes de massa micelial por bandeja, sendo que o volume de $300 \mathrm{~mL}$ foi superior aos demais (Fig. 11).

Os conídios obtidos com volume de $300 \mathrm{~mL} / \mathrm{ban}$ deja apresentaram comprimento e largura típicos da espécie (115,66 a 147,01 $\mu \mathrm{m}$ de comprimento e 14,01 a $15,20 \mu \mathrm{m}$ de largura, respectivamente), conforme Simmons (1982).

Maior porcentagem de conídios tingidos pelo azul de algodão foi verificada com a utilização dos volumes de 150 e $300 \mathrm{~mL}$ (Tabela 1). A capacidade dos esporos de absorverem esse pigmento revela sua maior integridade (Abbas et al., 1995), característica certamente fundamental para a manutenção da viabilidade e infectividade. Entretanto, a utiliza-

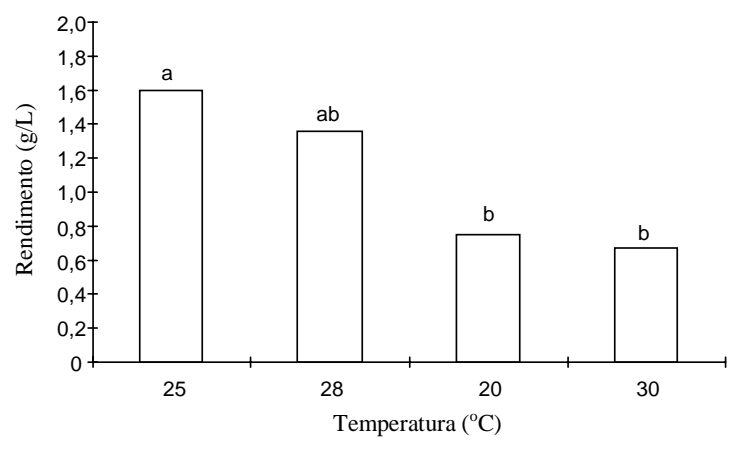

FIG. 8. Efeito da temperatura durante a exposição da massa micelial para esporulação e secagem no rendimento de massa fúngica seca de Alternaria cassiae.

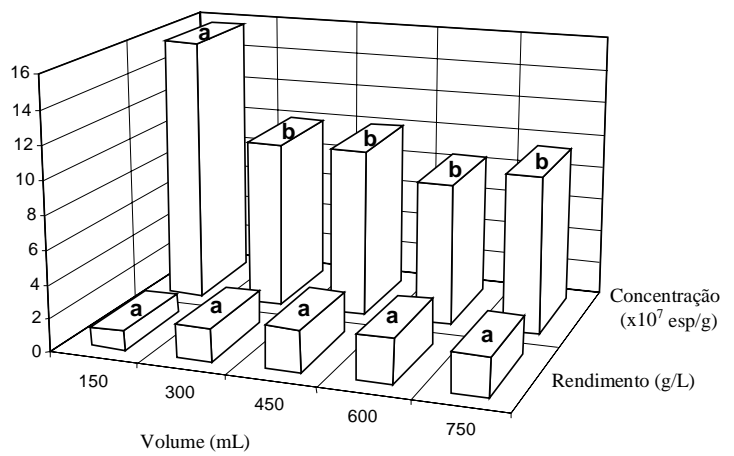

FIG. 9. Efeito do volume de massa micelial exposta por bandeja, para esporulação, sobre a produção de inóculo de Alternaria cassiae.

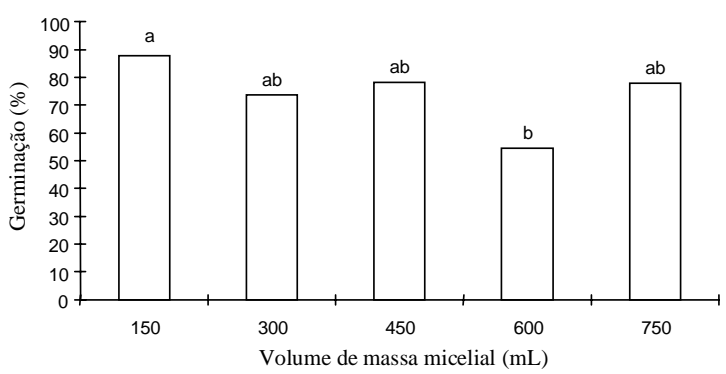

FIG. 10. Efeito do volume de massa micelial, em bandejas para esporulação, na viabilidade dos esporos de Alternaria cassiae.

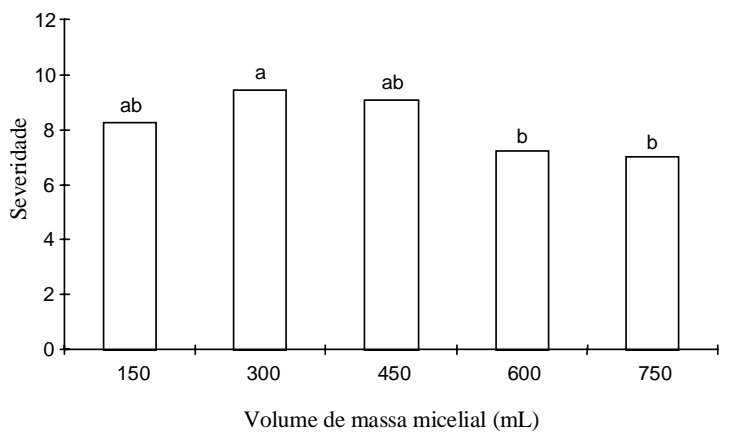

FIG. 11. Efeito do volume de massa micelial, em bandejas para esporulação, na infectividade dos esporos de Alternaria cassiae em fedegoso. Severidade da infecção obtida através de escala de notas de 1 a 9 .

Pesq. agropec. bras., Brasília, v.35, n.3, p.533-541, mar. 2000 
TABELA 1. Coloração, pelo azul de algodão, de conídios de Alternaria cassiae obtidos a partir de diferentes volumes de massa micelial por bandeja ${ }^{1}$.

\begin{tabular}{cc}
\hline Volume $(\mathrm{mL})$ & Conídios tingidos $(\%)$ \\
\hline 150 & $100,00 \mathrm{a}$ \\
300 & $94,03 \mathrm{ab}$ \\
450 & $85,41 \mathrm{bc}$ \\
600 & $77,65 \mathrm{c}$ \\
750 & $63,92 \mathrm{~d}$ \\
\hline
\end{tabular}

${ }^{1}$ Médias seguidas pela mesma letra não diferem entre si pelo teste de Duncan a $5 \%$ de probabilidade.

ção de menores volumes de homogeneizado de micélio apresenta-se vantajosa também pelo fato de requerer menor tempo para secagem, que é de cinco a seis dias, enquanto para volumes iguais ou superiores a $450 \mathrm{~mL}$, este processo requer um tempo mínimo de oito dias.

\section{Efeito da luminosidade na esporulação e na qua- lidade do inóculo}

O regime de luz durante a exposição da massa micelial para esporulação e secagem exerceu marcante influência sobre as características avaliadas (Fig. 12). Os maiores rendimentos de massa fúngica seca foram obtidos com incubação do homogeneizado de micélio em regime de escuro contínuo. O menor número médio de tubos germinativos evidentes, por conídio, foi também verificado com este tratamento (Tabela 2), que entretanto não diferiu significativamente do tratamento com 24 horas de luz alternada, quanto à concentração de esporos por grama de massa fúngica produzida. Não foram observadas variações quanto à porcentagem de conídios tingidos pelo azul de algodão, que foi próxima de 100\%, em todos os tratamentos. Quanto aos aspectos morfométricos, verificou-se uma tendência de acréscimo no comprimento do conídio, em presença de luz, evidenciando a influência da luminosidade na morfologia de conídios de A. cassiae, que também foi anteriormente constatada por Allen et al. (1982), com a espécie A. helianthi (Tabela 2).

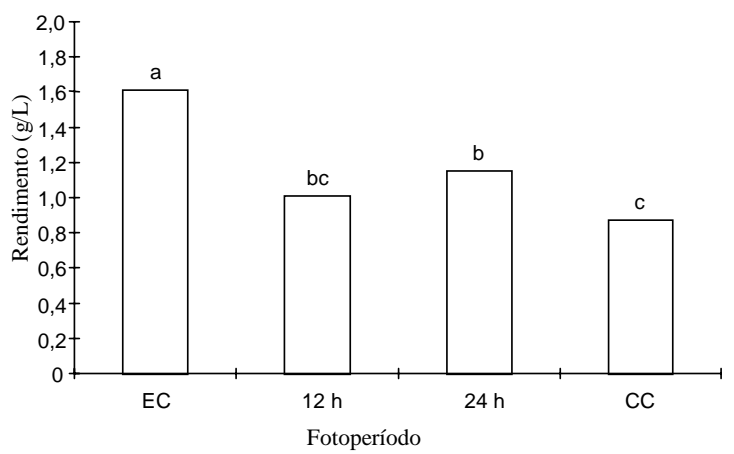

FIG. 12. Efeito da luminosidade na produção de inóculo de Alternaria cassiae (EC- escuro contínuo; 12 h e 24 h - tempo de alternância de fotoperíodo; CC - claro contínuo).

TABELA 2. Influência da luminosidade sobre a esporulação de Alternaria cassiae ${ }^{1}$.

\begin{tabular}{cccc}
\hline $\begin{array}{c}\text { Foto- } \\
\text { período }^{2}\end{array}$ & $\begin{array}{c}\mathrm{N}^{\mathrm{o}} \text { de tubos } \\
\text { germinativos }\end{array}$ & $\begin{array}{c}\text { Comprimento do } \\
\text { conídio }(\mu \mathrm{m})\end{array}$ & $\begin{array}{c}\text { Conc. } \\
\left(\mathrm{x} 10^{8} \mathrm{esp} / \mathrm{g}\right)\end{array}$ \\
\hline $\mathrm{EC}$ & $0,205 \mathrm{c}$ & $62,55 \mathrm{~b}$ & $4,01 \mathrm{a}$ \\
$12 \mathrm{~h}$ & $0,625 \mathrm{bc}$ & $81,64 \mathrm{a}$ & $2,34 \mathrm{~b}$ \\
$24 \mathrm{~h}$ & $1,060 \mathrm{~b}$ & $74,26 \mathrm{ab}$ & $3,14 \mathrm{ab}$ \\
$\mathrm{CC}$ & $1,737 \mathrm{a}$ & $67,39 \mathrm{ab}$ & $1,95 \mathrm{~b}$ \\
\hline
\end{tabular}

${ }^{1}$ Médias seguidas pela mesma letra não diferem entre si pelo teste de Duncan a $5 \%$ de probabilidade.

2 EC: escuro contínuo; CC: claro contínuo; 12 h: 12 horas de claro/escuro alternados; $24 \mathrm{~h}$ : 24 horas de claro/escuro alternados.

Para Walker (1983), o isolado de A. cassiae, registrado como bioerbicida sob o nome de CASST nos Estados Unidos, esporula profusamente apenas quando exposto a luz solar direta ou submetido a radiação sob luz incandescente. No entanto, variabilidade entre isolados quanto à capacidade de esporulação sob diferentes regimes de luz é comum entre fungos fitopatogênicos. O fato de o isolado CG593 esporular bem sob regime de escuro contínuo simplifica a metodologia de produção de inóculo em larga escala.

\section{CONCLUSÕES}

1. O meio V-8 caseiro, sem adição de $\mathrm{CaCO}_{3}$, é adequado para produção de inóculo de $A$. cassiae; 
a incubação deve ocorrer em volume de $200-250 \mathrm{~mL}$ de meio (cerca de $50 \%$ do volume do frasco) sob agitação ( $250 \mathrm{rpm})$ durante 48 horas.

2. A esporulação é favorecida por incubação da massa micelial a $25^{\circ} \mathrm{C}$ e escuro contínuo.

3. A adoção de $300 \mathrm{~mL}$ de massa fúngica por bandeja possibilita a secagem rápida, sem comprometer a qualidade do inóculo.

\section{REFERÊNCIAS}

ABBAS, H.K.; EGLEY, G.H.; PAUL, R.N. Effect of conidia production temperature on germination and infectivity of Alternaria helianthi. Phytopathology, Saint Paul, v.85, p.677-682, 1995.

ALLEN, S.J.; BROWN, J.F.; KOCHMAN, J.K. Effects of temperatures, dew period, and light on the growth and development of Alternaria helianthi. Phytopathology, Saint Paul, v.73, p.893-896, 1982.

BORGES NETO, C.R. Estudos sobre Cercospora caricis Oudem. como agente potencial de biocontrole da tiririca (Cyperus rotundus L.). Brasília : UnB, 1997. 123p. Tese de Mestrado.

CHARUDATTAN, R. Biological control of weeds: an international overview. In: SIMPÓSIO DE CONTROLE BIOLÓGICO, 5., 1996, Foz do Iguaçu. Anais. Curitiba : PJ Comunicação \& Eventos, 1996. p. 270-282.

CHARUDATTAN, R.; WALKER, H.L.; BOYETTE, C.D.; RINDINGS, W.H.; TEBEEST, D.O.; DYKE,
C.G. van; WORSHAM, A.D. Evaluation of Alternaria cassiae as a mycoherbicide for sicklepod (Cassia obtusifolia) in regional field tests. Auburn : University of Auburn, 1986. 19p. (Southern Cooperative Service Bulletin, 317).

CROWLEY, R.H.; TEEM, D.H.; BUCHANAN, G.A.; HOVELAND, C.S. Responses of Ipomoea spp. and Cassia spp. to preemergence applied herbicides. Weed Science, Champaign, v.27, p.531-535, 1979.

MELLO, S.C.M.; RIBEIRO, Z.M. de A. Fitopatógenos como agentes de controle de plantas daninhas. In: MELO, I.S.; ZEVEDO, J.L. (Eds.). Controle biológico. Jaguariúna : Embrapa, 1998. p.97-128.

PITELLI, R.A. Weed-soybean interference studies in Brazil. In: COPPING, L.G.; GREEN, M.B.; REES, R.T. (Eds.). Pest management in soybean. London : Elsevier, Applied Science, 1992. p.282-289,

SIMMONS, E.G. Alternaria themes and variations. Mycotaxon, Ithaca, v.14, p.17-43, 1982.

SMITH, D.S.; ONIONS, A.H.S. The preservation and maintenance of living fungi. Farnham Royal : CAB International Mycological Institute, 1983.51p.

WALKER, H.L. Control of sicklepod, showy crotalaria and coffee senna with fungal pathogen. U.S.A. n.4, 390.360. Mar. 10, 1982, June 28, 1983.

WALKER, H.L. Seedling blight of sicklepod caused by Alternaria cassiae. Plant Disease, Saint Paul, v.66, p.426-428, 1982. 